\title{
Central serous retinopathy and hand-foot-mouth disease: coincidence or causation?
}

This article was published in the following Dove Press journal: International Medical Case Reports Journal

\author{
Selina Taylor \\ Maureen Khan ${ }^{2}$ \\ Shams Zaidi ${ }^{3}$ \\ Umair Alvi ${ }^{4}$ \\ Yaqoot Fatima' \\ 'Centre for Rural and Remote Health, \\ James Cook University, Mount Isa, \\ QLD, Australia; ${ }^{2}$ Sunshine Coast \\ University Hospital, Sunshine Coast, \\ QLD, Australia; ${ }^{3}$ Mackay Hospital \\ and Health Service, Mackay, QLD, \\ Australia; ${ }^{4}$ Cairns Hospital, Cairns, \\ QLD, Australia
}

Introduction: The clinical and pathological correlation between hand-foot-mouth disease (HFMD) and ocular complications has not yet been established. However, individual case reports indicate a trend that may be the emergence of a new burden of the previous self-limiting virus. This virus is particularly prevalent in childcare centers and poses an infectious disease risk for this workplace.

Objectives: The primary objective of this case report is to describe an unusual clinical record of a patient who developed central serous retinopathy while unwell with HFMD. Discussion of management strategies for this workplace, its staff, and visitors is also included.

Methods: This was an observational case report that was identified and reported retrospectively. For comparison, a search of the literature to identify similar ocular complications of HFMD was also undertaken. Results from this search, in addition to international data and prevention and management strategies are also provided.

Results: A total of 13 individual case reports with ocular associations, including this clinical record, were identified in the literature worldwide. The median age was 33 years, and three patients $(23 \%)$ were female. No treatment or management guidelines for ocular complications of HFMD have been identified.

Conclusion: Severe and potentially life-threatening complications of a seemingly harmless childhood illness are represented sporadically in the literature. The requirement for research and evaluation into this emerging occupational hazard area is necessary for improved prevention, management, and treatment strategies to be developed.

Keywords: hand-foot-mouth disease, hand-foot-mouth, ocular complications, central serous retinopathy, childcare center

\section{Background}

Occupational exposure to infectious diseases is well described in the literature; however, specific considerations for hand-foot-mouth disease (HFMD) in childcare centers has limited evidence. ${ }^{1}$ With an estimated 473,000 children in formal child care in Australia, infectious disease risk for childcare workers is an important consideration. ${ }^{1}$ In addition, workplace exposure to visitors and carers of children attending childcare centers is a significant factor for disease transmission. ${ }^{1}$

Central serous retinopathy (CSR) is a chorioretinal disease of the eye that is characterized by an accumulation of subretinal fluid in the posterior pole. ${ }^{2}$ Hyperpermeability of choroidal vessels and retinal pigment-epithelium dysfunction may also contribute to the disease's etiology, and hypercortisolic states may play a role in triggering episodes. ${ }^{2}$
Correspondence: Yaqoot Fatima Centre for Rural and Remote Health (Mount Isa), James Cook University, PO Box 2572, Mount Isa Hospital Campus, Mount Isa, QLD 4825, Australia Tel +6I 747454529

Email yaqoot.fatima@jcu.edu.au 
This report presents a case in which a patient who after attending a childcare center initially presented with HFMD, then developed vision disturbance that was later diagnosed as CSR. The pathogenic connection between the two illnesses has limited evidence in the literature; however, this presents an unusual case for consideration.

\section{Hand-foot-mouth disease}

HFMD is a systemic viral illness that was discovered in 1969 and is primarily caused by Coxsackie A16 and enterovirus $71 .^{3-5}$ Clinical features typically include fever, painful papules, and blisters over the extremities and genitalia and ulceration of the mouth, palate, and pharynx. ${ }^{3}$ HFMD can affect both adults and children; however, it is more common in children under the age of 10 years. ${ }^{6}$ This mild vesicular eruption occurs most commonly among groups of children in childcare centers, due to rapid transmission processes. ${ }^{6}$ HFMD is highly contagious, with transmission occurring through oral respiratory secretions, touch contact with the blistered areas, fecal-oral transmission (most common), or from contaminated environmental sources. ${ }^{4,6,7}$ The clinical course of HFMD is described in Box 1 and can be used to relate to the patient described in the case. The pathogenesis of HFMD involves enteroviral implantation in the gastrointestinal tract (buccal mucosa and ileum) with extension into the regional lymph nodes. ${ }^{4}$ Viremia occurs 72 hours later as a result of seeding of the oral mucosa and skin of the hands and feet. ${ }^{4}$

\section{Clinical record}

A 32-year-old male Caucasian refrigeration mechanic presented to his general practitioner with initial symptoms of severe sore throat (ulcerations visible), mild fever, malaise, and body aches. The patient was healthy, with no history of immunosuppression or smoking. The symptoms had been present for 36-48 hours upon presentation. The patient had a body mass index of 26 . His personal history was significant: with an 18-month-old infant at home attending a childcare

Box I Clinical course of hand-foot-mouth disease

Incubation period 3-5 days
Initial fever, headache, and malaise
Sore throat and mouth
Vesicular rash develops after I-2 days, beginning as a red macule and
then progressing to vesicles
Vesicles present on hands, palms, and soles, and less commonly on
limbs, buttocks, and genitals
Lesions resolve in 3-5 days and heal without scarring
Virus is excreted in feces and saliva for several weeks, and children
are infectious until blisters have disappeared

Note: Data from Murtagh and Rosenblatt. ${ }^{6}$ center 2 days per week. The patient regularly entered the childcare center to drop off and pick up his child. He had an unremarkable medical history, except childhood asthma and mild atopic associations. His ocular history indicated complete vision with no impairment in either eye.

The general practitioner initially diagnosed a bacterial throat infection and prescribed amoxicillin $500 \mathrm{mg}$ three times daily for 5 days. Two days later, papular vesicles began to develop on the palms and soles of the feet (Figure 1). Four days after the initial onset of symptoms, the patient had developed extensive blisters extending beyond the palmar surfaces of hands and feet and onto the face, nasal cavity, ears, scalp, and buttocks. The patient rated the pain from the vesicles as 7/10 and required moderate pain management.

The patient also developed complete central visual field loss in one eye and mild visual disturbance in the other on day 6. He presented to the emergency department and was referred to the local optometrist for investigation. Physical examination was classic of features of HFMD and followed the expected clinical course to resolution of blisters, so serological testing was not indicated. Blood tests were baseline, mainly for liver function associated with virus, and normal, as expected with Coxsackie virus or HFMD.

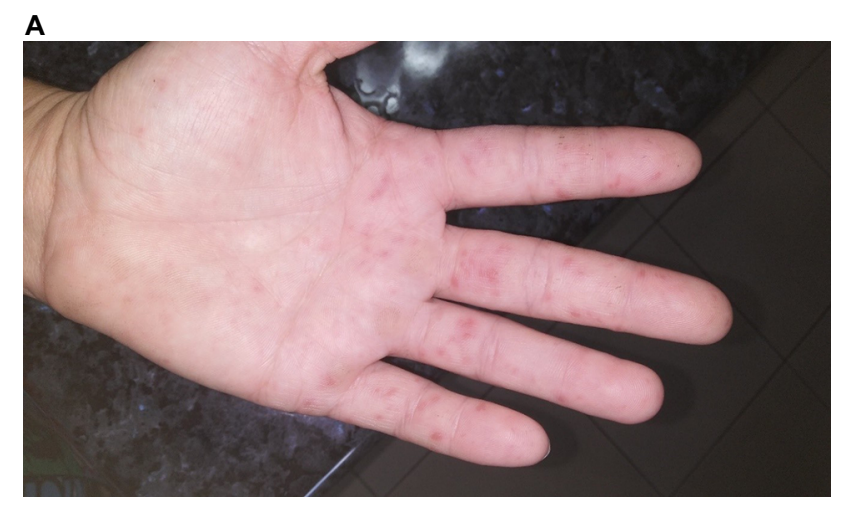

B

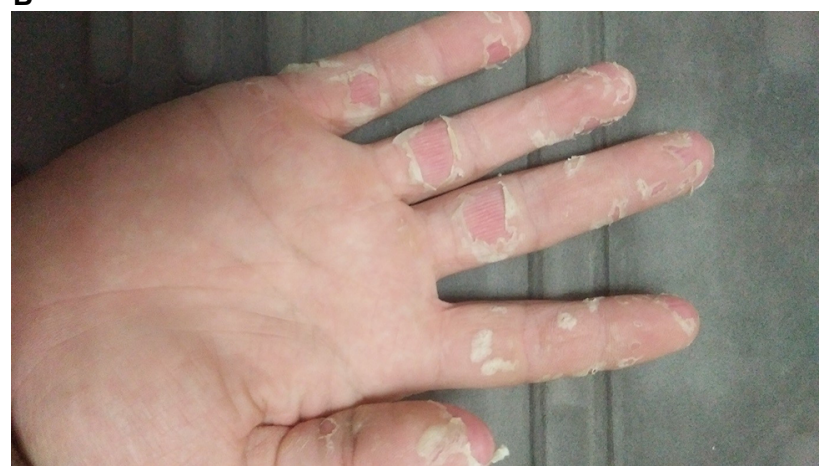

Figure I Palmar-vesicle images.

Notes: (A) At 3 days after initial symptom presentation; (B) at 12 days after initial symptom presentation. 
Ophthalmic examination included visual acuity. The visual field was examined, which was not a valid exam, as visual acuity was low. Slit-lamp examination did not reveal any floaters or cells in the anterior chamber or any corneal abrasions on fluorescein staining. Optical coherence tomography was conducted and reviewed by a visiting ophthalmologist. Figure 2 shows an optical coherence tomography retinal thickness map and horizontal high-resolution images of the right eye showing central serous chorioretinopathy. The ophthalmologist made a diagnosis of CSR and the senior medical officer diagnosed HFMD potentially associated with the CSR. The patient's dermatological symptoms resolved over $\sim 10$ days; however, ocular symptoms improved but did not completely resolve. The patient's vision in the right eye remains impaired, due to scarring, and no further improvement is expected. He was referred to the ophthalmology clinic in a regional hospital.

Written informed consent was provided by the patient to have the case details and any accompanying images published. No institutional approval was required to publish this case report.

\section{Discussion HFMD epidemiology}

HFMD is extremely transmissible, with infection rates of almost $100 \%$ in young children. ${ }^{8}$ In the past 20 years, this virus has been the main contributor to HFMD worldwide and been responsible for large outbreaks in Southeast Asia. ${ }^{7}$ In Taiwan during 1998 and China during 2008-2010, there was an epidemic of enterovirus 71 , during which $\sim 500,000$ infections and 126 deaths were recorded for China. ${ }^{8}$ These epidemics were associated with central nervous system disease (eg, brain-stem encephalitis, seizures), myocarditis, and pulmonary hemorrhage. ${ }^{8}$ Deaths recorded were primarily for the age group of children $<5$ years. ${ }^{8}$

Australia and New Zealand have also reported outbreaks of HFMD in recent years; however, it is difficult to determine the frequency at which outbreaks may be occurring, as this disease is not notifiable to any public health unit. ${ }^{79}$ From December 2012 until May 2013, an epidemic of enterovirus 17 occurred in Sydney. ${ }^{7}$ This outbreak resulted in 119 children being admitted to a tertiary hospital with fever, lethargy, myoclonus, and skin rash. ${ }^{7}$ Of note, only $24 \%$ of the cases

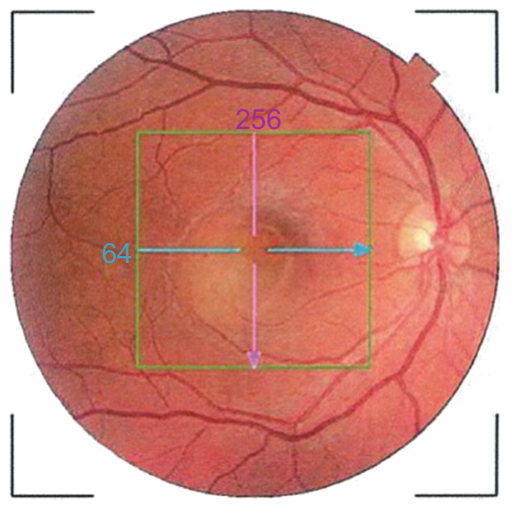

Retinal thickness map ILM---OS/RPE/Red-free

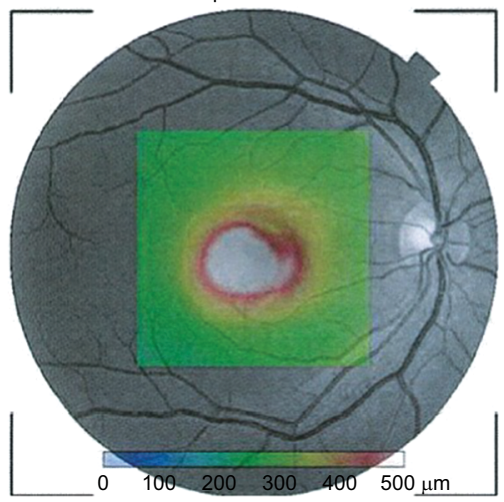

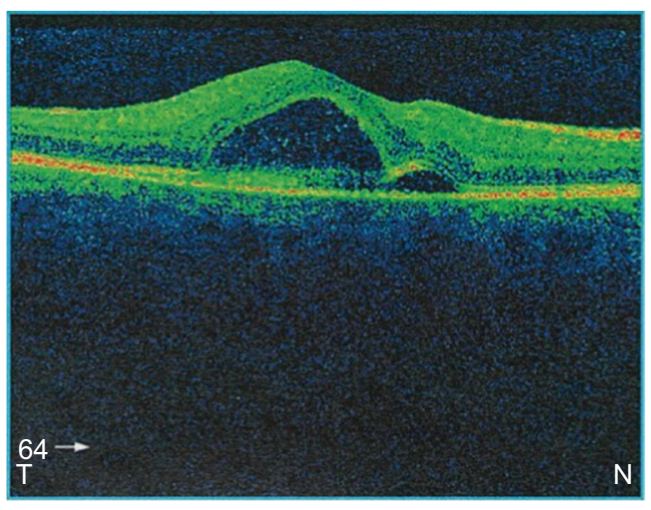

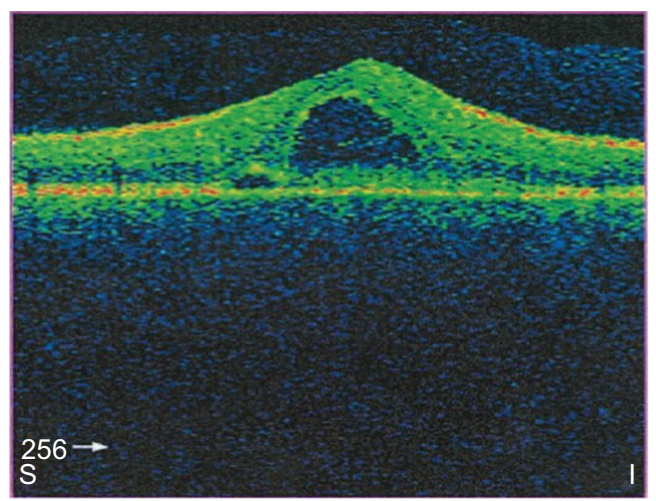

Figure 2 OCT retinal thickness map and horizontal high-resolution images of the right eye showing central serous chorioretinopathy. Abbreviations: OCT, optical coherence tomography; ILM, internal limiting membrane; RPE, retinal pigment epithelium. 
presented with classical HFMD symptoms, and 30 presented with severe neurological symptoms. ${ }^{7,9}$

In the same reporting period, Auckland, New Zealand recorded 98 cases of presumed HFMD compared with 18 cases in the previous year for this period. ${ }^{9}$ It was noted that the mouth ulcers and skin lesions were more widespread than typical HFMD, and nail shedding after the rash was frequently reported. ${ }^{9}$ One of these cases reported suspected encephalitis with laboratory-confirmed Coxsackie virus A6 involvement. ${ }^{9}$ It has been identified that the epidemic activity was associated with three specific lineages, two of which (B3 and B4) had not been described previously. ${ }^{5}$ These epidemics indicate that enterovirus 71 and Coxsackie A6 are likely to remain a public health concern for Australia, and surveillance and prevention strategies will be essential for effective management. ${ }^{7}$

\section{HFMD complications}

The literature presents a variety of atypical presentations and complications of HFMD. These presentations are provided in Table 1 and provide a summary of the unusual cases that have been reported. ${ }^{10-14}$ Although there have been individual case reports published, there is limited literature investigating whether HFMD is presenting in more severe cases than its previous mild self-limiting illness. ${ }^{11}$ In addition, there have been multiple case reports of immunocompetent adults contracting self-limiting HFMD from contact with young infected children. ${ }^{15-17}$

\section{Ocular complications}

Ocular complications, in particular central serous retinopathies associated with HFMD, have been reported sporadically in the literature, making this case report unique. In 2000, there was a case reported of monofocal outer retinitis associated with HFMD caused by Coxsackie virus in a healthy 36-yearold male. ${ }^{18}$ Due to the close association between cutaneous eruption and the onset of visual symptoms, it was suggested that the retinal lesion was caused by Coxsackie virus B4 or B3. ${ }^{18}$ This case report aligns closely with the clinical record presented in this report.

Similarly, in 2015, a 35-year-old female presented with acute maculopathy with concurrent HFMD infection. ${ }^{19}$ This patient had characteristic dermatological symptoms of HFMD and had been in contact with the virus from her daughter. ${ }^{19}$ Agrawal et al produced results from a systematic review of ocular associations of HFMD worldwide and identified 11 previous cases with a mean age of 33 years and only two occurring in females. ${ }^{19}$ The ocular morphology represented by these cases included chorioretinitis, vasculitis, exudates, macular detachment, retinitis, retinal detachment, and discoloration of the macula. ${ }^{19}$

Interestingly, none of the identified ocular complications associated with HFMD included CSR. Literature reporting on CSR has described the condition as rare and exacerbated by steroids and stress. ${ }^{20-22}$ CSR currently has no effective treatment available, but there is one case report of the use of topical nonsteroidal anti-inflammatory ointment that may have been useful in management, but as a single case, no definitive recommendations can be made..$^{23}$

\section{Prevention and management strategies}

Outbreaks, severe disease, and case reports of spread of the disease to immunocompetent adults has prompted the WHO

Table I Representation of atypical presentations and complications of HFMD reported in the literature

\begin{tabular}{|c|c|c|c|c|}
\hline Author & $\begin{array}{l}\text { Patient } \\
\text { age }\end{array}$ & Description & Causative agent & $\begin{array}{l}\text { Atypical presentation/ } \\
\text { complication }\end{array}$ \\
\hline Feder et al" & $\begin{array}{l}\text { 9-month-old } \\
\text { male }\end{array}$ & $\begin{array}{l}\text { Vesiculobullous lesions extending over the whole body } \\
\text { and onychomadesis on big toes }\end{array}$ & $\begin{array}{l}\text { Confirmed } \\
\text { Coxsackie virus } \mathrm{A} 6\end{array}$ & $\begin{array}{l}\text { Vesiculobullous lesions } \\
\text { and onychomadesis }\end{array}$ \\
\hline Stewart et $\mathrm{al}^{14}$ & $\begin{array}{l}\text { 37-year-old } \\
\text { male }\end{array}$ & $\begin{array}{l}\text { Widespread, crusted, pruritic papules on scalp, ears, and } \\
\text { face and targetoid painful vesicular eruption on hands } \\
\text { and feet with accompanying neurological symptoms and } \\
\text { arthritis }\end{array}$ & $\begin{array}{l}\text { Confirmed } \\
\text { Coxsackie virus A6 }\end{array}$ & $\begin{array}{l}\text { Neurological symptoms } \\
\text { and arthritis }\end{array}$ \\
\hline Shikuma et $\mathrm{al}^{13}$ & $\begin{array}{l}\text { 22-year-old } \\
\text { male }\end{array}$ & $\begin{array}{l}\text { Severe mucosal lesions with rapid erosion impairing the } \\
\text { ability to consume food; immunocompetent adult }\end{array}$ & $\begin{array}{l}\text { Suspected } \\
\text { Coxsackie virus } 16 \text {, } \\
\text { not confirmed }\end{array}$ & $\begin{array}{l}\text { Severe mucosal eroding } \\
\text { lesions }\end{array}$ \\
\hline Legey et al' ${ }^{12}$ & $\begin{array}{l}\text { 76-year-old } \\
\text { male }\end{array}$ & $\begin{array}{l}\text { Initial presentation of acute-onset fever, lumbar pain, and } \\
\text { dyspnea; close contact with child with HFMD I week } \\
\text { earlier }\end{array}$ & $\begin{array}{l}\text { Confirmed } \\
\text { Coxsackie virus A6 }\end{array}$ & Fatal pneumonitis \\
\hline $\begin{array}{l}\text { Chatproedprai } \\
\text { et al }{ }^{10}\end{array}$ & $\begin{array}{l}\text { Eight } \\
\text { children: } 10 \\
\text { months old } \\
\text { to } 12 \text { years } \\
\text { old }\end{array}$ & $\begin{array}{l}\text { Large vesicles resembling varicella eruption, crust on } \\
\text { scalp, widespread purpura-like lesions, Gianotti-Crosti } \\
\text { syndrome, and desquamation }\end{array}$ & Various & $\begin{array}{l}\text { Unusual skin } \\
\text { manifestations }\end{array}$ \\
\hline
\end{tabular}

Abbreviation: HFMD, head-foot-mouth disease. 
to produce a guide for clinical management and public health response. ${ }^{24}$ It has been proposed that without intervention, the public health impact and spread of the disease will continue to intensify. ${ }^{24}$ Current measures being undertaken to prevent and control HFMD worldwide include improved surveillance, education on good hygiene and sanitation, assistance for childcare centers during outbreaks, strengthened infectioncontrol measures in communities and healthcare facilities, improved case management for patients presenting with severe illness or unusual symptoms, and monitoring and evaluation. ${ }^{24}$

As enterovirus 71 is not susceptible to any newly developed antiviral agents, the development of a vaccine for the future is also being considered. ${ }^{5,24}$ It is hoped that the development of an effective live-attenuated vaccine would result in effective control of future epidemics. ${ }^{5} \mathrm{~A}$ formalin-inactivated enterovirus 71 vaccine have been developed and evaluated in human clinical trials. ${ }^{25}$ Although this vaccine was found to elicit full protection against enterovirus 71 , it failed to prevent the Coxsackie A6 virus. ${ }^{25}$ As enterovirus 71 has been responsible for many outbreaks worldwide, this vaccine was being evaluated for effect in China in 2014, and government vaccination program decision makers are considering its use in practice. ${ }^{26}$

Improved emergency department surveillance and better liaison with primary healthcare providers may improve the knowledge and management associated with this highly virulent disease. ${ }^{9}$ There is an urgent need to identify appropriate detection tools and best-practice guidelines to prevent transmission and effectively manage epidemics. ${ }^{27}$ In a literature review conducted in 2017, control measures for HFMD epidemics included environmental disinfection, facility closure (between 6 and 30 days), promotion of personal or hand hygiene, isolation of symptomatic cases, body checks, and health education. ${ }^{27}$ Many of these measures are undertaken in child-care facilities currently; however, closure anecdotally does not occur, and the high virulence and rapid transmission makes the impact of control measures limited in the demographic of young children. ${ }^{27}$

\section{Occupational prevention and management strategies}

Child-care workers are exposed to a high prevalence of infectious diseases through their close contact with children. ${ }^{1,28}$ Job tasks, including physical care and personal hygiene, lead to exposure to biological hazards and infectious diseases. ${ }^{28,29}$ In an effort to limit disease transmission and reduce workplace exposure, a risk management process is essential for implementation in all child-care settings. ${ }^{26,30}$ The following strategies may be utilized to reduce infectious disease risk to children, child-care workers, and visitors to occupationalchildcare settings:

- robust hygiene measures (eg, hand washing, nappy changes $)^{31}$

- adequate supplies of protective equipment (eg, gloves, face masks) ${ }^{31}$

- maintenance of an immunization register of all children and staff attending ${ }^{31}$

- adherence to policy guidelines for cleaning of all equipment and surfaces ${ }^{31}$

- exclusion of staff and children presenting with signs of illness for the defined exclusion period ${ }^{26,31}$

- separating children in nappies from older children ${ }^{1}$

- providing timely communication to carers and staff of confirmed cases of infectious disease ${ }^{31}$

\section{Conclusion}

It is evident that infectious diseases, particularly HFMD, have high prevalence in child-care settings, which places child-care workers and visitors to childcare centers at risk of disease transmission. From the case reported, it can be identified that seemingly self-limiting illnesses, such as HFMD, may have serious and potentially permanent impact. It can be noted that although literature demonstrating ocular complications of HFMD is limited, as the disease is not notifiable, many complications may be occurring worldwide without being reported.

Improved surveillance in both the primary care and emergency care settings would provide increased knowledge regarding the incidence, demographics, and occurrence of both atypical presentations and unusual complications. This information would allow for the development of robust guidelines to reduce severe illness, permanent disability, and death that is occurring from HFMD. Additionally, more data in this area may also result in improved prevention and management strategies being implemented in the workplace.

\section{Disclosure}

The authors report no conflicts of interest in this work.

\section{References}

1. Ferson MJ. Infection control in child care settings. Commun Dis Intell. 1997;21(22):333-338.

2. Pouw AE, Olmos de Koo LC. Oral rifampin for central serous retinopathy: a strategic approach in three patients. Ophthalmic Surg Lasers Imaging Retina. 2015;46(1):98-102. 
3. Ventarola D, Bordone L, Silverberg N. Update on hand-foot-and-mouth disease. Clin Dermatol. 2015;33(3):340-346.

4. Wolff K, Johnson RA, Saavedra AP, Fitzpatrick TB, editors. Fitzpatrick's color atlas and synopsis of clinical dermatology. In: Color Atlas and Synopsis of Clinical Dermatology. 7th ed. New York: McGraw-Hill Medical; 2013.

5. Mcminn PC. An overview of the evolution of enterovirus 71 and its clinical and public health significance. FEMS Microbiol Rev. 2002;26(1): 91-107.

6. Murtagh J, Rosenblatt J. John Murtagh's General Practice. 6th ed. North R, editor. NSW: McGraw-Hill Education; 2015.

7. Zander A, Britton PN, Navin T, Horsley E, Tobin S, Mcanulty JM. An outbreak of enterovirus 71 in metropolitan Sydney: enhanced surveillance and lessons learnt. Med J Aust. 2014;201(11):663-666.

8. Kasper DL, Fauci AS, Hauser SL, Longo DL, Jameson JL, Loscalzo J, editors. Harrison's Manual of Medicine. 19th ed. New York: McGraw Hill Education; 2016.

9. Hayman R, Shepherd M, Tarring C, Best E. Outbreak of variant handfoot-and-mouth disease caused by coxsackievirus A6 in Auckland, New Zealand: New Zealand coxsackievirus A6 outbreak. J Paediatr Child Health. 2014;50(10):751-755.

10. Chatproedprai S, Tempark T, Wanlapakorn N, Puenpa J, Wananukul S, Poovorawan Y. Unusual skin manifestation of hand, foot and mouth disease associated with coxsackievirus A6: cases report. Springerplus. 2015;4:362.

11. Feder HM, Bennett N, Modlin JF. Atypical hand, foot, and mouth disease: a vesiculobullous eruption caused by Coxsackie virus A6. Lancet Infect Dis. 2014;14(1):83-86.

12. Legay F, Lévêque N, Gacouin A, et al. Fatal coxsackievirus A-16 pneumonitis in adult. Emerg Infect Dis. 2007;13(7):1084-1086.

13. Shikuma E, Fujisawa A, Tanioka M, Matsumura Y, Miyachi Y, Yoshiki M. Letter: an adult case of hand-foot-mouth disease showing severe mucous involvement. Dermatol Online J. 2011;17(12):15.

14. Stewart CL, Chu EY, Introcaso CE, Schaffer A, James WD. Coxsackievirus A6-induced hand-foot-mouth disease. JAMA Dermatol. 2013;149(12):1419-1421.

15. Shin JU, Oh SH, Lee JH. A case of hand-foot-mouth disease in an immunocompetent adult. Ann Dermatol. 2010;22(2):216-218.

16. Kaminska K, Martinetti G, Lucchini R, Kaya G, Mainetti C. Coxsackievirus A6 and hand, foot and mouth disease: three case reports of familial child-to-immunocompetent adult transmission and a literature review. Case Rep Dermatol. 2013;5(2):203-209.
17. Omaña-Cepeda C, Martínez-Valverde A, del Mar Sabater-Recolons M, Jané-Salas E, Marí-Roig A, López-López J. A literature review and case report of hand, foot and mouth disease in an immunocompetent adult. BMC Res Notes. 2016;9:165.

18. Haamann P, Kessel L, Larsen M. Monofocal outer retinitis associated with hand, foot, and mouth disease caused by coxsackievirus. $\mathrm{Am} J$ Ophthalmol. 2000;129(4):552-553.

19. Agrawal R, Bhan K, Balaggan K, Lee RW, Pavesio CE, Addison PK. Unilateral acute maculopathy associated with adult onset hand, foot and mouth disease: case report and review of literature. $J$ Ophthalmic Inflamm Infect. 2015;5:2.

20. Saab M, Ullal J. Central serous retinopathy: an uncommon sign of an uncommon disease. Endocrine Practice. 2017;23:170.

21. Chu JL, Tyberg J. Central serous retinopathy: an unusual cause of acute visual loss. CJEM. 2013;15(5):311-313.

22. Editor. Prednisolone: central serous retinopathy: case report. Reactions Weekly. 2017;1672:228-228.

23. Semes L. Central serous retinopathy helped by NSAIDs. Optometry Times. 2015;7(12):19.

24. World Health Organisation. A Guilde to Clinical Management and Public Health Response for Hand, Foot and Mouth Disease (HFMD). Geneva, Switzerland; 2011.

25. Liu CC, Chow YH, Chong P, Klein M. Prospect and challenges for the development of multivalent vaccines against hand, foot and mouth diseases. Vaccine. 2014;32(47):6177-6182.

26. Australian Government National Health and Medical Research Council. Staying Healthy in Child Care Preventing infectious diseases in child care. Canberra. 2015.

27. Chan JH, Law CK, Hamblion E, Fung H, Rudge J. Best practices to prevent transmission and control outbreaks of hand, foot, and mouth disease in childcare facilities: a systematic review. Hong Kong Med J. 2017;23(2):177-190.

28. Cordell R, Pickering L, Henderson FW, Murph J. Infectious diseases in childcare settings. Emerg Infect Dis. 2004;10(11):e9.

29. Bright KA, Calabro K. Child care workers and workplace hazards in the United States: overview of research and implications for occupational health professionals. Occup Med. 1999;49(7):427-437.

30. Safe Work Australia. How to Manage Work Health and Safety Risks: Code of practice. Canberra: Australian Government; 2011.

31. Worksafe Western Australia. Reducing the Risk of Infectious Diseases in Child Care Workplaces. Perth, Australia; 2002.
International Medical Case Reports Journal

\section{Publish your work in this journal}

The International Medical Case Reports Journal is an international, peer-reviewed open-access journal publishing original case reports from all medical specialties. Previously unpublished medical posters are also accepted relating to any area of clinical or preclinical science. Submissions should not normally exceed 2,000 words or
4 published pages including figures, diagrams and references. The manuscript management system is completely online and includes a very quick and fair peer-review system, which is all easy to use. Visit $\mathrm{http}: / /$ www.dovepress.com/testimonials.php to read real quotes from published authors. 